\title{
Utilization of methionine sulphoxide and methionine sulphone by the young rat
}

\author{
By L. R. NJAA \\ Governmental Vitamin Laboratory, Norwegian Fisheries Research Institute, \\ Bergen, Norway
}

(Received I2 February 1962-Revised 2 April 1962)

According to Miller (1956) methionine in fish meal is partly destroyed during the production process. Lea, Parr \& Carpenter ( $195^{8}$ ) held it 'obviously possible' that methionine sulphoxide may be formed in fish meal in the presence of peroxidizing fat. They seem to imply that animals would utilize the sulphoxide less efficiently than methionine. This suggestion is at variance with the results of Bennett (1939) who found that DL-methionine sulphoxide could replace DL-methionine in the diet of the growing albino rat, though she found later that DL-methionine sulphone could not (Bennett, I94I). Njaa (I96r) suggested that the sulphoxide is probably utilized at a slower rate than methionine.

In the experiments reported here, methionine sulphoxides synthesized from DL-, D- or L-methionine and methionine sulphone synthesized from L-methionine were tested for methionine activity in young rats given a soya-bean meal diet ( $N$ jaa, $\mathrm{I}_{96 \mathrm{I}}$ ). The results indicated that $L$-methionine sulphoxide was utilized to the same extent as was methionine, and that D-methionine sulphoxide was about $50 \%$ and DL-methionine sulphoxide about $75 \%$ as effectively utilized. L-methionine sulphone was found to have no methionine activity. The equal utilization of DL-, D- and L-methionine (Berg, I959) was substantiated.

\section{EXPERIMENTAL}

\section{Preparation of the sulphoxides and the sulphone}

The methionine sulphoxides were synthesized by the method of Toennies \& Kolb (I939) as modified by Waelsch, Owades, Miller \& Borek (I946). Hydrochloric acid was used instead of hydrobromic acid for dissolving the methionine in the preparation of the sulphoxide used in Expt I. It was, therefore, probably contaminated with some ammonium chloride.

L-methionine sulphone was synthesized by the method of Toennies \& Kolb (I94I) except that concentrated ammonia was used instead of amylamine for the neutralization of the perchloric acid.

\section{Purity of the compounds synthesized}

The compounds were analysed for nitrogen by the method of Ma \& Zuazaga (1942). They were further tested for purity by a circular-paper chromatographic technique (P. Juvvik \& K. Michelsen, I962, to be published) the solvent being acetone containing $15 \%(v / v)$ of water and $\mathrm{r} \%(\mathrm{v} / \mathrm{v})$ of conc. ammonia. The chromatograms were run 
overnight. The solvent front moved off the paper so that $R_{F}$ s could not be determined. Ninhydrin $(0.3 \%(\mathrm{w} / \mathrm{v})$ in methanol) was used as the developing reagent. It was established that none of the common amino acids would have escaped notice by the technique used. The method gave good separation of methionine, methionine sulphone and methionine sulphoxide, named in the order of decreasing distance from the starting line.

Table I. Characteristics of the samples of methionine sulphoxide and methionine sulphone used in the experiments

\begin{tabular}{|c|c|c|c|c|c|}
\hline Compound & $\begin{array}{c}\text { Expt } \\
\text { no. }\end{array}$ & $\begin{array}{c}\text { Sample } \\
\text { no. }\end{array}$ & $\begin{array}{c}\text { Nitrogen } \\
\text { content* } \\
(\%)\end{array}$ & $\begin{array}{l}\text { Calculated } \\
\text { content } \\
\text { of } \\
\text { compound } \\
\text { in the } \\
\text { particular } \\
\text { sample } \dagger \\
(\%)\end{array}$ & $\begin{array}{l}\text { Approximate } \\
\text { content } \\
\text { of } \\
\text { sulphone } \\
\text { in } \\
\text { sample } \\
(\%)\end{array}$ \\
\hline DL-methionine sulphoxide & $\begin{array}{l}\text { I } \\
2,3\end{array}$ & $\begin{array}{l}\mathrm{I} \\
2\end{array}$ & $\begin{array}{l}8 \cdot 89 \\
8 \cdot 13\end{array}$ & $\begin{array}{l}98 \\
96\end{array}$ & $\begin{aligned}>1, & <2 \\
& <1\end{aligned}$ \\
\hline L-methionine sulphoxide & $\begin{array}{l}2,3 \\
4\end{array}$ & $\begin{array}{l}3 \\
4\end{array}$ & $\begin{array}{l}8 \cdot I I \\
8 \cdot 3 I\end{array}$ & $\begin{array}{l}96 \\
98\end{array}$ & $\begin{array}{l}\simeq \mathrm{I} \\
<\mathrm{I}\end{array}$ \\
\hline D-methionine sulphoxide & 4 & 5 & $8 \cdot 28$ & 98 & $<\mathrm{I}$ \\
\hline L-methionine sulphone & 6 & 6 & $7 \cdot 8 \mathrm{I}$ & I0O & - \\
\hline
\end{tabular}

The samples tested were chromatographically pure with the exception that the methionine sulphoxides contained traces of the sulphone. This is in agreement with the finding of Dent ( 1948 ) that $\mathrm{H}_{2} \mathrm{O}_{2}$ treatment of methionine sulphoxide may produce traces of the sulphone. The amounts present were estimated roughly by running chromatograms of each sample together with dilution series of the sulphone. Results are given in Table I. No account was taken of the sulphone contents in samples I-5 when the daily supplements given to the rats were calculated. The assumed sulphoxide contents given were arrived at from the nitrogen determinations. On the assumption that samples 2-5 contained only residual solvents and water besides the sulphoxide, the contents were calculated from the ratios between the determined and the theoretical nitrogen contents. It was mentioned above that sample I might have been contaminated with small amounts of ammonium chloride. The sulphoxide content of this sample was accordingly calculated on the assumption that its somewhat high nitrogen content could be accounted for by regarding the sample as a mixture of methionine sulphoxide and ammonium chloride. Sample 6 was assumed to be $100 \%$ pure methionine sulphone. As no account was taken of the sulphone contents in the samples of the sulphoxide, the daily supplements of the latter were probably slightly less than intended. 


\section{Animals and technique}

In all experiments the apparent urinary recovery of ingested nitrogen ( $\mathrm{Njaa}, \mathrm{I} 959 b$, 1961) (roo $U / I$, where $U=$ urinary nitrogen $(\mathrm{mg} /$ day) and $I=$ nitrogen intake (mg/day)) was determined in three or four groups of rats weighing between 60 and $90 \mathrm{~g}$. A high value for $100 U / I$ corresponds to a low utilization of the protein. Six groups of three or four litter-mate rats were used in each experiment, one rat from each litter being allotted to each treatment $(\mathrm{Njaa}$, I959a). Within litters the rats were of the same sex and of approximately the same body-weight. The mean initial bodyweights of the groups within an experiment differed by less than $\mathrm{I}_{5} \mathrm{~g}$. The diet had the percentage composition: partly dextrinized potato starch 54.3 , sugar 20 , arachis oil 5 , extracted soya-bean meal $16 \cdot 7$, salts (Sure, I94I) 4 . The soya-bean meal was the same as that used by $\mathrm{Njaa}(\mathrm{I} 96 \mathrm{I})$. It contained $47 \cdot 8 \%$ crude protein $(\mathrm{N} \times 6 \cdot 25)$ and hence the diet contained about $8 \%$. A new batch of diet was prepared for each experiment and kept in a closed container in the animal room. The daily amount of food offered and completely eaten was $10 \mathrm{~g} / \mathrm{rat}$ in all experiments except in Expt 2 in which it was $8 \mathrm{~g}$. The daily rations were weighed to within $0.1 \mathrm{~g}$. The amino-acid supplements were given at a level equivalent to $\mathrm{I} \cdot 5 \mathrm{~g}$ methionine/100 $\mathrm{g}$ crude protein. Aqueous solutions of the supplements were pipetted into the daily rations together with the vitamin solution and water ( $\mathrm{Njaa}, \mathrm{1959} a$ ). The diets were given for 9 days, urine was collected during the last 5 days. Nitrogen was determined by the method of Ma \& Zuazaga (1942).

\section{Design of experiments}

In all experiments rats given DL-methionine served as positive and rats given glycine as negative controls.

Expt I. DL-methionine sulphoxide (sample I) was tested alone and as a I : I mixture with DL-methionine.

Expts 2 and 3. DL-methionine sulphoxide (sample 2) and L-methionine sulphoxide (sample 3 ) were compared.

Expt. 4. L-methionine (sample 4) and D-methionine sulphoxide (sample 5) were compared.

Expt 5. DL-, D- and L-methionine were compared.

Expt 6. L-methionine sulphone (sample 6) was tested for methionine activity.

\section{RESULTS}

Mean values for roo $U / I$, initial body-weights and daily weight gains of the rats are given in Table 2. Between experiments no consistent relationship was evident between the daily weight gains and the corresponding roo $U / I$ values. Moreover, between groups of rats of similar body-weights receiving identical treatments there were obvious differences between roo $U / I$ values, and between daily weight gains. On this account, no special explanation is suggested for the fact that too $U / I$ values obtained at daily food intakes of 8 and $10 \mathrm{~g} / \mathrm{rat}$ were not always appreciably different (e.g. in the groups given glycine in Expts I, 2, 5, 6). It is suggested that comparisons between observed values should only be made within experiments. 
In my experience with short-term experiments, treatment differences are more consistently detected by use of nitrogen balance values, than by gain in weight. In the experiments described here, protein digestibility was assumed to be negligibly affected by the treatments, wherefore the term roo $U / I$ could be used as a measure of nitrogen balance. The following considerations are mainly based upon the observations of this quantity.

Table 2. Effect on apparent urinary recovery of ingested nitrogen (100 $U / I$ ) and weight gain of rats of supplementing a soya-bean meal diet with methionines $(M)$, methionine sulphoxides (MSO) or L-methionine sulphone ( $\left.\mathrm{L}-\mathrm{MSO}_{2}\right)$

(Mean values for groups of six rats)

\begin{tabular}{|c|c|c|c|c|c|c|}
\hline \multirow[t]{2}{*}{ Supplement } & Expt I & Expt 2 & Expt 3 & Expt 4 & Expt 5 & Expt 6 \\
\hline & \multicolumn{6}{|c|}{$100 U / I$} \\
\hline DL-M & $32 \cdot 3$ & $38 \cdot 4$ & $29 \cdot 7$ & $3 I \cdot T$ & $3^{6 \cdot x}$ & $43 \cdot 1$ \\
\hline $\mathrm{L}-\mathrm{M}$ & - & - & - & - & $37 \cdot 0$ & - \\
\hline $\mathrm{D}-\mathrm{M}$ & - & $\ldots$ & - & - & $35 \cdot 4$ & $\ldots$ \\
\hline DL-MSO & $38.8(37 \cdot 5)$ & $43 \cdot 1(42 \cdot 8)$ & $32 \cdot 8(33.4)$ & - & - & - \\
\hline L-MSO & - & $36.5\left(3^{8} \cdot 4\right)$ & $27 \cdot 8(29 \cdot 7)$ & $3 I \cdot 3(3 I \cdot I)$ & - & - \\
\hline D-MSO & $\rightarrow$ & - & - & $42 \cdot 3(40 \cdot 0)$ & - & - \\
\hline $\mathrm{DL}-\mathrm{M}+\mathrm{DL}-\mathrm{MSO}(\mathrm{I}: \mathrm{I})$ & $34^{\circ} 6\left(34^{\circ} 9\right)$ & - & - & - & - & $\ldots$ \\
\hline $\mathrm{L}-\mathrm{MSO}_{2}$ & - & 一 & - & - & 一 & $55^{\prime} \mathrm{I}\left(55^{\circ} \circ\right)$ \\
\hline Glycine & $53 \cdot 2$ & $55 \cdot 8$ & $44 \cdot 4$ & $48 \cdot 9$ & $5 \mathrm{I} \cdot \mathrm{I}$ & $55^{\circ} \circ$ \\
\hline Standard ( 5 df) & $\pm 1 \cdot \infty 0$ & $\pm 1 \cdot 02$ & \pm 0.93 & $\pm 0.6_{5}$ & $\pm x \cdot 27$ & - \\
\hline error (ro df) & - & - & - & - & $\longrightarrow$ & $\pm x \cdot 23$ \\
\hline
\end{tabular}

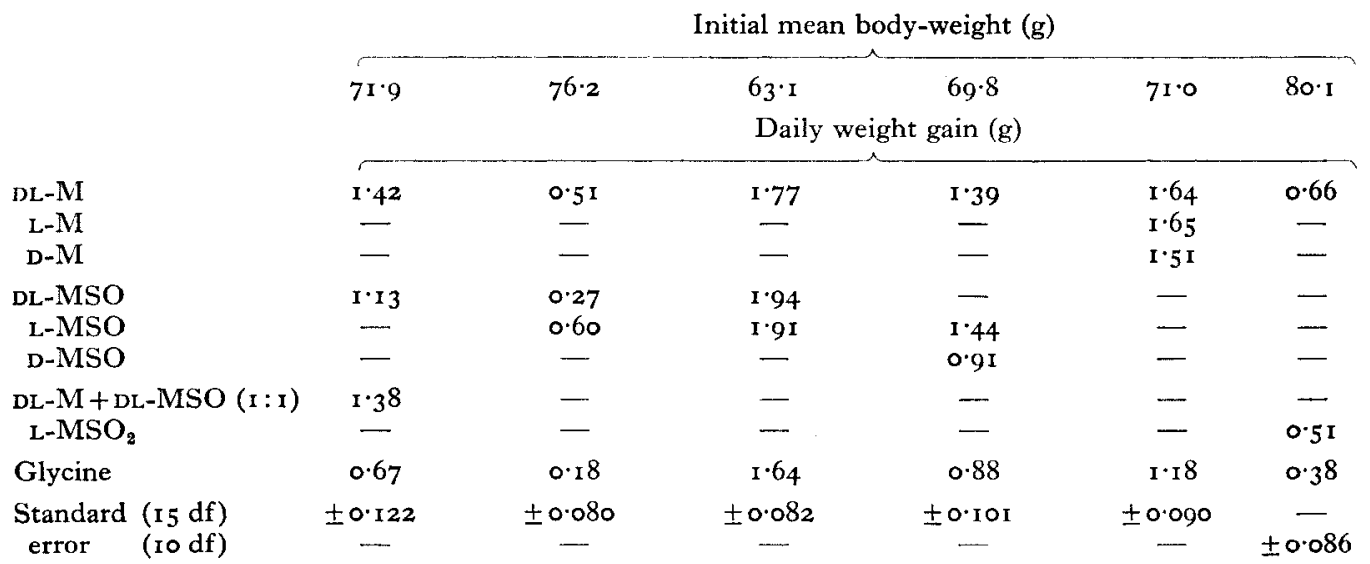

Values in parentheses were calculated on the assumption that DL-methionine sulphoxide has $75 \%$ of the potency of DL-methionine, L-methionine sulphoxide $100 \%, \mathrm{D}$-methionine sulphoxide $50 \%$ and L-sulphone $0 \%$. $U$, urinary nitrogen $(\mathrm{mg}) ; I$, nitrogen intake $(\mathrm{mg})$.

The I0o $U / I$ values indicated a poorer utilization of DL-methionine sulphoxide than of DL-methionine (Expts I-3). L-methionine sulphoxide and DL-methionine were utilized to the same extent (Expts 2-4) whereas D-methionine sulphoxide was less efficiently utilized (Expt 4). The utilizations of DL-, D- and L-methionine were not significantly different (Expt 5). L-methionine sulphone as compared with glycine 
did not improve the roo $U / I$ value (Expt 6). The general picture was the same when judged by the daily weight gains except in Expt 3 in which all groups gained weight at a similar rate.

The potencies of the samples tested relative to DL-methionine were estimated on the assumption that roo $U / I$ varied linearly with the content of available methionine in the diet. Glycine was assumed to be $\circ \%$ and DL-methionine $100 \%$ available. The results indicated the following approximate potencies: L-methionine sulphoxide $100 \%$, DL-methionine sulphoxide $75 \%$, D-methionine sulphoxide $50 \%$, L-methionine sulphone $\% \%$. The theoretical values for I0o $U / I$ calculated from these potencies are shown in parentheses in Table 2.

\section{DISCUSSION}

Oxidation of L-methionine to the sulphoxide stage did not reduce its availability as a methionine source and further oxidation to the sulphone stage resulted in complete loss of activity (Expts 2-4, 6). Thus, if oxidation is held responsible for the part of the methionine in fish meal that is 'rendered unavailable during processing' (Miller 1956), oxidation must have proceeded beyond the sulphoxide stage. Oxidation by fat peroxides to the sulphone stage seems unlikely. Njaa (1962) has shown that treatment of methionine on filter-paper with $30 \%(\mathrm{w} / \mathrm{w}) \mathrm{H}_{2} \mathrm{O}_{2}$ gives, at a $\mathrm{pH}$ of about $6 \cdot 0$, only sulphoxide, whereas a mixture of sulphoxide and sulphone is obtained between a $\mathrm{pH}$ of 6 and a $\mathrm{pH}$ of $\mathrm{r} \cdot 4$, below which only the sulphone is obtained. The $\mathrm{pH}$ of the fish during processing into fish meal is about 6.0. It is possible, however, that the small amount of molybdenum present in fish (Westerfeld \& Richert, 1953; Vinogradov, 1953) may catalyse the oxidation of methionine to the sulphone stage (Toennies \& Kolb, 194I; Dent, 1948). No methionine sulphone was detected on paper chromatograms of hydrochloric acid hydrolysates of herring meals with the potassium iodoplatinate reagent of Winegard, Toennies \& Block (1948). My experience with this reagent indicates, however, that it is not of the required sensitivity for the detection of the small amounts of sulphone that might be formed in herring meal. The vain task of searching for methionine sulphoxide in hydrochloric acid hydrolysates was discussed by Njaa (1962). Whether methionine sulphoxide and sulphone are formed from methionine during the production of herring meal needs further investigation. Conceivably methionine may be rendered partly unavailable by oxidation to the sulphoxide if the presence of the latter in peptide linkage would reduce the rate of proteolysis. The importance of this rate for the utilization of protein was stressed by, among others, Clandinin (1949) and Sheffner, Adachi \& Spector (1956).

The observation that DL- and D-methionine sulphoxides were less efficiently utilized by the young rat than were DL-methionine and L-methionine sulphoxide (Expts I-4) is at variance with the observation that DL-methionine sulphoxide can replace DLmethionine in the diet of the rat (Bennett, 1939). The suggestion of Njaa (196r) that the two latter substances might be equally well utilized at low but not at high growth rates was not substantiated (Expts 2 and 3, Table 2). It is probable, therefore, that the different results must be explained by the different techniques used: Bennett 
(I939) measured growth in a long-term experiment whereas in the investigation described here roo $U / I$ values were determined in experiments of short duration.

The different utilization of the sulphoxides referred to above, and the fact that the methionines were equally well utilized (Expt 5) indicate that the utilization of the sulphoxides is influenced by the asymmetries about the carbon atom as well as by those about the sulphur atom. Toennies \& Kolb (1939) suggested that there might be differences in the biological effects among the four possible diastereoisomers present in DL-methionine sulphoxide. This suggestion was substantiated by the experiments with micro-organisms of Lampen, Jones \& Perkins (1947), Borek \& Waelsch (1947) and Shockman \& Toennies (1954). One of the possible explanations of the different availabilities of the sulphoxides for the young rat reported here is that one of the two diastereoisomers formed from $\mathrm{D}$-methionine is completely unavailable. However, verification or rejection of any hypothesis on this point must await tests on rats with the individual diastereoisomers.

\section{SU M MARY}

I. Methionine sulphoxide prepared from DL-, D- and L-methionine, L-methionine sulphone, and $\mathrm{D}$ - and L-methionine were tested on young rats, as supplements to a soya-bean meal diet, with rats given DL-methionine as positive and rats given glycine as negative controls.

Protein utilization was measured by assessing the urinary nitrogen excretion as a percentage of the nitrogen intake.

2. The sulphoxides prepared from DL-, D- and L-methionine were about $75,5^{\circ}$ and $100 \%$ respectively as potent as DL-methionine.

3. L-methionine sulphone was not utilized as a source of methionine.

4. DL-, D- and L-methionine were equally well utilized.

5. It is suggested that if oxidation during processing renders a portion of the methionine in fish meal unavailable it must have proceeded beyond the sulphoxide stage.

6. One explanation of the results obtained with the methionine sulphoxides is that one of the diastereoisomers formed from D-methionine is completely unavailable to the young rat.

\section{REFERENCES}

Bennett, M. A. (1939). Biochem. F. 33, 1794.

Bennett, M. A. (1941). F. biol. Chem. 141, 573.

Berg, C. P. (1959). In Protein and Amino Acid Nutrition. Ch. 4. [A. A. Albanese, editor.] New York: Academic Press Inc.

Borek, E. \& Waelsch, H. (1947). Arch. Biochem. 14, I43.

Clandinin, D. R. (1949). Poult. Sci. 28, 128.

Dent, C. E. (1948). Biochem. F. 43, I69.

Lampen, J. O., Jones, M. J. \& Perkins, A. B. (1947). Arch. Biochem. r3, 33.

Lea, C. H., Parr, L. J. \& Carpenter, K. J. (1958). Brit. F. Nutr. 12, 297.

Ma, T. S. \& Zuazaga, G. (1942). Industr. Engng Chem. (Anal.) 14, 280.

Miller, D. S. (1956). F. Sci. Fd Agric. 7, 337.

Njaa, L. R. (1959a). Brit. F. Nutr. 13, 137.

Njaa, L. R. (1959b). Brit. F. Nutr. 13, 142.

Njaa, L. R. (196I). F. Sci. Fd Agric. 12, 757.

Njaa, L. R. (1962). Acta chem. scand. 16, 1359. 
Sheffner, A. L., Adachi, R. \& Spector, H. (1956). 7. Nutr. 6o, 507.

Shockman, G. D. \& Toennies, G. (1954). Arch. Biochem. Biophys, 50, I.

Sure, B. (r94r). F. Nutr. 22, 499.

Toennies, G. \& Kolb, J. J. (1939). F. biol. Chem. r28, 399.

Toennies, G. \& Kolb, J. J. (r94 I). F. biol. Chem. r40, r 3r.

Vinogradov, A. P. (1953). The Elementary Chemical Composition of Marine Organisms. Ch. 21, p. 534. New Haven: Sears Foundation for Marine Research, Yale University.

Waelsch, H., Owades, P., Miller, H. K. \& Borek, E. (1946). F. biol. Chem. 166, 273.

Westerfeld, W. W. \& Richert, D. A. (1953). F. Nutr. 51, 85.

Winegard, H. M., Toennies, G. \& Block, R. J. (1948). Science, ro8, 506. 